
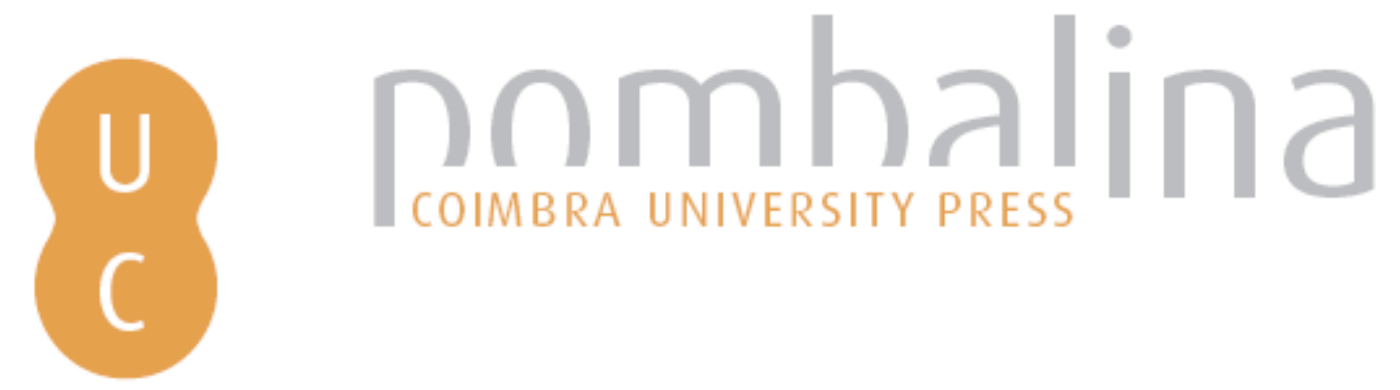

\title{
Vulnerabilidade a incêndios na Europa Mediterrânea: abordagem conceptual e a utilização de dados de satélite
}

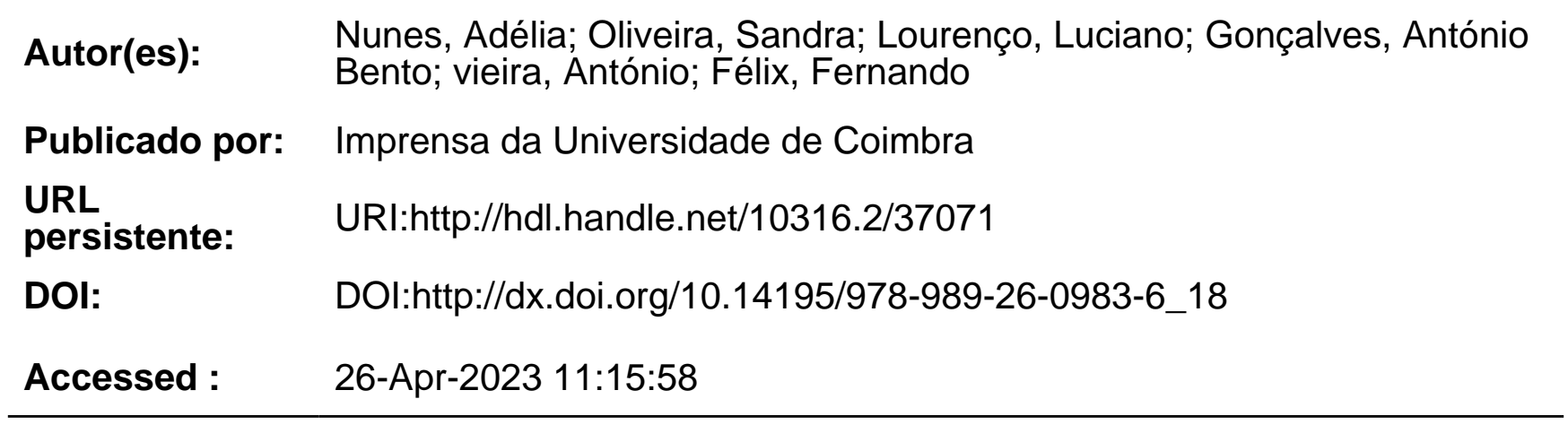

A navegação consulta e descarregamento dos títulos inseridos nas Bibliotecas Digitais UC Digitalis, UC Pombalina e UC Impactum, pressupõem a aceitação plena e sem reservas dos Termos e Condições de Uso destas Bibliotecas Digitais, disponíveis em https://digitalis.uc.pt/pt-pt/termos.

Conforme exposto nos referidos Termos e Condições de Uso, o descarregamento de títulos de acesso restrito requer uma licença válida de autorização devendo o utilizador aceder ao(s) documento(s) a partir de um endereço de IP da instituição detentora da supramencionada licença.

Ao utilizador é apenas permitido o descarregamento para uso pessoal, pelo que o emprego do(s) título(s) descarregado(s) para outro fim, designadamente comercial, carece de autorização do respetivo autor ou editor da obra.

Na medida em que todas as obras da UC Digitalis se encontram protegidas pelo Código do Direito de Autor e Direitos Conexos e demais legislação aplicável, toda a cópia, parcial ou total, deste documento, nos casos em que é legalmente admitida, deverá conter ou fazer-se acompanhar por este aviso.

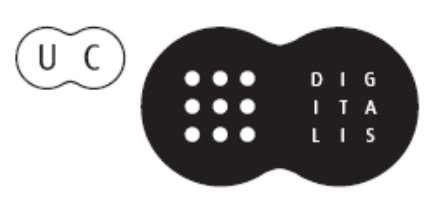




\section{$\forall$ \\ TAS DAS I JORNADAS LUSÓFONAS DE CIÊNCIAS E TECNOLOGIAS DE INFORMAÇÃO GEOGRÁFICA}

Editores

José Gomes dos Santos

Cidália Fonte

Rui Ferreira de Figueiredo

Alberto Cardoso

Gil Gonçalves

José Paulo Almeida

Sara Baptista 


\title{
A RTIGO 18
}

\section{VULNERABILIDADE A INCENDIOS NA EUROPA MEDITERRÂNEA ABORDAGEM CONCEPTUAL E A UTILIZAÇÃo DE DADOS DE SATÉLITE}

\author{
NUNES, Adélia ${ }^{1}$; OLIVEIRA, Sandra ${ }^{2}$, LOURENÇO, Luciano ${ }^{1}$; \\ BENTO-GONÇALVES, António ${ }^{3}$; VIEIRA, António ${ }^{3}$ E FÉLIX, Fernando ${ }^{2}$
}

\footnotetext{
${ }^{1}$ Departamento de Geografia - Faculdade de Letras da Universidade de Coimbra (Portugal) Largo da Porta Férrea, 3004-530 Coimbra, Portugal. Tel: +351 239857000; email: adelia.nunes@ci.uc.pt; luciano@uc.pt 2 Núcleo de Investigação Científica de Incêndios Florestais - Universidade de Coimbra (Portugal) Aeródromo da Lousã, Chã do Freixo, 3200-395 Lousã, Portugal. Tel: +351 239992251; email: sandra.oliveira@ uc.pt; ffelix@fl.uc.pt

3 Departamento de Geografia - Universidade do Minho (Portugal) Campus de Azurém, 4800-058 Guimarães, Portugal. Tel: +351 253510560; email: bento@geografia.uminho.pt; vieira@geografia.uminho.pt
}

\section{RESUMO}

A frequência de incêndios e a magnitude dos seus impactes na região mediterrânea determinam a necessidade de melhorar o suporte técnico e o acesso à informação, de modo a lidar mais eficazmente com situações de emergência e diminuir a suscetibilidade a incêndios. O projeto PREFER, onde participam as Universidades de Coimbra e do Minho, pretende responder a esta necessidade através da produção de cartografia múltipla baseada em dados atualizados de forma sistemática, com destaque para a utilização de imagens de satélite, de média a muito alta resolução, para obtenção desses dados. No âmbito da prevenção e preparação para emergências, estão a ser desenvolvidos os mapas de vulnerabilidade, de valor económico e de risco sazonal. A definição de vulnerabilidade é fundamental para identificar as variáveis a integrar na sua análise. Na sua abordagem conceptual englobaram- 
-se três componentes principais: exposição, sensibilidade e capacidade de antecipação e resposta. A metodologia definida para a recolha e processamento de variáveis, de cariz natural ou antrópico e oriundas de fontes diversas, é apresentada através da descrição da sua aplicação no contexto da deteção remota e Sistemas de informação geográfica. Serão, ainda, apresentados alguns produtos cartográficos preliminares para a área de estudo nacional, a integrar na exposição, uma das componentes da vulnerabilidade.

\title{
PALAVRAS-CHAVE
}

Vulnerabilidade, Risco de incêndio, Imagens de satélite, Prevenção, Cartografia.

\section{VULNERABILITY TO FIRES IN MEDITERRANEAN EUROPE. CONCEPTUAL APPROACH AND THE USE OF SATELLITE DATA}

\begin{abstract}
The frequency of forest fires and the magnitude of their impacts in the Mediterranean region, indicate the need to improve the technical support and the accessibility to reliable data, in order to cope more efficiently with emergency situations and decrease the susceptibility to fires. The PREFER project, which counts with the participation of the Universities of Coimbra and Minho, aims to respond to this need by developing multiple cartographic products, based on data which can be systematically updated, with emphasis on data obtained from satellite images of medium to very high resolution. In the framework of fire prevention and emergency preparedness, maps of vulnerability, economic value and seasonal fire risk are being developed. The definition of the vulnerability concept is paramount to identify the variables required to include in the analysis. The conceptual approach of vulnerability encompasses the integration of three components: exposure, sensitivity and coping capacity. The methodology defined to collect the data and process the variables, either natural or anthropic and coming from different sources, is described in the context of its application in remote sensing and geographical information systems. Additionally, the preliminary results and cartographic products obtained to the national study area, related to the analysis of exposure, one of the components of vulnerability, are also presented.
\end{abstract}

\section{KEYWORDS}

Vulnerability, Fire risk, Satellite images, Prevention, Cartography.

\section{INTRODUÇÃO}

A ocorrência de incêndios florestais é uma das principais ameaças à sustentabilidade dos espaços florestais e à segurança das populações 
na Europa Mediterrânea. Entre 2000 e 2012, no conjunto dos países do Sul da Europa mais afetados por incêndios, nomeadamente Portugal, Espanha, França, Itália e Grécia, foi registada uma média anual de 55 mil incêndios e de 410 mil hectares de área ardida (JRC, 2013). Estes países representam a maior área arborizada da Europa, que varia entre 38\% em Portugal e 29\% em França (WORLD BANK, 2011).

O clima de tipo mediterrâneo que os carateriza, com períodos intercalados de precipitação, que promove o crescimento da vegetação, e períodos de tempo quente e seco, é favorável à ocorrência de incêndios (PAUSAS, 2004), sendo, no entanto, a maioria das ocorrências nestes países causadas por atividades antrópicas (BADIA et al., 2011; LEONE et al., 2003; LOURENÇO et al., 2011/12; LOURENÇO et al., 2013; MARTÍNEZ et al., 2009; VAZQUÉZ \& MORENO, 1993).

O tipo de povoamento humano, definido pela coexistência de aglomerados urbanos, infraestruturas e vegetação (florestas, matos e áreas agrícolas, por exemplo), favorece igualmente a elevada frequência de incêndios (LAMPIN-MAILLET et al., 2011). Para além disso, as alterações no uso do solo verificadas nas últimas décadas, com o abandono das áreas rurais e a diminuição do controlo sobre as práticas tradicionais de uso do fogo, aumentam a suscetibilidade a incêndios nestes países (BADIA et al., 2011; BENTO-GONÇALVES et al, 2012; MOREIRA et al., 2011; SAN-MIGUEL-AYANZ et al, 2012).

O número de incêndios e a área ardida variam substancialmente de ano para ano e entre países. Com efeito, em Portugal, foram os anos de 2003 e 2005 aqueles que registaram os maiores valores de área ardida, enquanto em Espanha foram os anos de 2012 e 2005 os que apresentaram maior área queimada, ao passo que na Grécia, um ano particularmente dramático, foi o de 2007 (JRC, 2013). Ora, os incêndios afetam diretamente a segurança das populações e colocam em risco vidas humanas, como se verificou na recente época de 2013 em Portugal, além de que influenciam negativamente o funcionamento dos ecossistemas e a proteção do solo (BENTO-GONÇALVES et al, 2012; BOWMAN et al., 2009, DWYER et al., 2000), bem como a qualidade do ar (CARVALHO et al., 2011; PECHONY \& SHINDELL 2010) e, ainda, a economia local (MAVSAR et al., 2012). 
A frequência dos incêndios e a magnitude dos seus impactes nesta região requerem, por um lado, uma gestão integrada nas suas diversas fases, desde a prevenção e preparação para situações de emergência até ao combate e recuperação de áreas ardidas, de forma a garantir o funcionamento eficaz das diversas estruturas de gestão da floresta e de proteção civil, assim como a aplicação das medidas de antecipação e de resposta mais adequadas. Por outro lado, a variabilidade espácio-temporal na ocorrência de incêndios e a diversidade de fatores que os influenciam, requerem a atualização regular de informação e a melhoria do suporte técnico de análise de dados, de forma a apoiar a distribuição atempada dos recursos disponíveis e a atuação eficaz dos meios no terreno.

O projecto PREFER $^{1}$ pretende responder a esta necessidade, através da disponibilização de informação harmonizada à escala europeia e atualizada sistematicamente com base em dados de satélite e tecnologias avançadas, e na produção de cartografia aplicada a diversas fases de gestão de incêndios, nomeadamente na prevenção e preparação para situações de emergência e na fase de recuperação pós-incêndios.

Iniciado no final de 2012 e com uma duração de três anos, este projeto europeu reúne a contribuição de oito instituições de vários setores (universidades, centros de investigação e empresas de tecnologia), dos cinco países da Europa Mediterrânea mais afetados por incêndios florestais. Para além disso, o projeto conta com a participação de diversos utilizadores finais, oriundos dos cinco países em estudo, os quais contribuem ao longo do processo de desenvolvimento dos produtos cartográficos, através da disponibilização de dados, da discussão de conceitos e terminologia e da avaliação da utilidade e aplicação dos produtos. O projeto PREFER baseia-se no estabelecimento de sinergias entre as diversas entidades que trabalham na gestão de incêndios, promovendo a interação entre a investigação científica e a aplicação prática.

Os produtos e serviços definidos no projeto distribuem-se por dois eixos principais:

1 PREFER: "Space-based Information Support for Prevention and Recovery of Forest Fires Emergency in the MediteRranean Area 
- Informação de apoio à fase de prevenção e preparação para incêndios florestais;

- Informação de apoio à fase de reabilitação e recuperação de áreas ardidas.

Este artigo tem como principal objetivo apresentar os produtos cartográficos que estão a ser desenvolvidos pelo Núcleo de Investigação Científica de Incêndios Florestais da Universidade de Coimbra, em parceria com a Universidade do Minho, e que, no âmbito da prevenção e preparação para incêndios, consistem nos mapas de vulnerabilidade, valor económico e risco de incêndio florestal.

\section{METOdOLOGiA E RESULTADOS PRELIMINARES}

A abordagem definida para a análise dos parâmetros antes mencionados, assim como para a recolha de dados e processamento das variáveis integradas na análise, são apresentados seguidamente.

\subsection{Abordagem conceptual}

Esta abordagem visa facultar elementos que permitam a compreensão dos produtos cartográficos a desenvolver no âmbito do projeto e que se explicitam a seguir.

\subsubsection{Vulnerabilidade e valor económico}

Os dados integrados e as técnicas aplicadas para a análise da vulnerabilidade dependem do significado atribuído a este conceito. Em sentido lato vulnerabilidade representa o potencial de perda (CUTTER, 2011). De acordo com os padrões internacionais, definidos pelas Nações Unidas (UNISDR, 2009), a vulnerabilidade reflete as condições determinadas por fatores físicos, sociais, económicos e ambientais ou por processos que aumentam a suscetibilidade de uma comunidade ao impacto de um processo potencialmente perigoso. A vulnerabilidade associa-se, então, ao grau de perda estimado, caso ocorra um incêndio, o qual pode afetar diversos setores: social, económico, ambiental, institucional (BIRKMANN, 2006). Neste sentido, a análise de vulnerabilidade deve integrar, por um 
lado, as diferentes dimensões do ambiente e da sociedade que podem sofrer perdas. Por outro lado, deve incluir também a capacidade dos sistemas naturais e humanos absorverem as mudanças e recuperarem dos danos sofridos (LAVOREL et al., 2007; TURNER et al., 2003).

No âmbito do projeto PREFER, a abordagem de vulnerabilidade integra três componentes principais (Figura 1):

a) Exposição

A exposição refere-se especificamente à presença de pessoas, bens ou outros elementos em áreas sujeitas a um potencial incêndio e que estão, por isso, sujeitas a perdas (UNISDR, 2009). Neste contexto, a exposição resulta da distribuição espacial de pessoas, edifícios, infraestruturas e tipos de ocupação do solo, em áreas onde existe probabilidade de ocorrência de incêndios;

b) Sensibilidade

A sensibilidade refere-se às condições que reduzem ou aumentam a capacidade dos elementos expostos responderem perante a ocorrência de um incêndio e de recuperarem dos seus impactes. O tipo de vegetação existente e o seu potencial comportamento perante o fogo, os materiais utilizados na construção dos edifícios, as caraterísticas demográficas da população, como a idade e o género, são circunstâncias que influenciam o tipo e a magnitude dos danos a que os elementos expostos estão sujeitos;

c) Capacidade de antecipação e de resposta

A capacidade de antecipação está associada à possibilidade de implementar ações com o intuito de reduzir a probabilidade de ocorrência e suscetibilidade a incêndios. Está relacionada com atividades de prevenção, aplicadas antes da ocorrência de um evento potencialmente perigoso, tais como a produção de cartografia de risco, as campanhas de prevenção e as medidas de ordenamento do território.

A capacidade de resposta reflete a possibilidade de implementar ações que permitam lidar com o evento de forma eficiente, reduzindo os potenciais danos e melhorando a capacidade de recuperação dos sistemas afetados. Está relacionado com o combate a incêndios, com serviços de emergência e assistência durante e após o evento, assim como com a recuperação de áreas ardidas e dos elementos afetados, integrando variáveis como a rede de estradas florestais, a localização dos pontos de água e dos quartéis de bombeiros ou as medidas de recuperação 
de áreas ardidas para evitar a erosão dos solos.

A capacidade de antecipação e de resposta influencia a resiliência dos elementos expostos.

\begin{tabular}{|c|c|}
\hline Componentes & Elementos / Variáveis \\
\hline & $\begin{array}{l}\text { Cobertura do solo (tipo de vegetação, uso do solo) } \\
\text { População (densidade e dispersão espacial) } \\
\text { Edificado (densidade e localização) } \\
\text { Infraestruturas (estradas, linhas elétricas) } \\
\text { Outros elementos ambientais (solo, cursos de água, } \\
\text { áreas protegidas) } \\
\text { Atividades económicas (agricultura, floresta) }\end{array}$ \\
\hline Sen & $\begin{array}{l}\text { Biofisica/ambiental (declive, cobertura do solo, } \\
\text { intensidade de precipitaçăo, erosão potencial do } \\
\text { solo, áreas de elevado interesse ecológico) } \\
\text { População (grupos etários, género, setor de trabalho) } \\
\text { Infra-estruturas (distância de edificios a área } \\
\text { florestada, acessos a áreas florestais) } \\
\text { Institucionais (acesso à saúde, educação) }\end{array}$ \\
\hline $\begin{array}{l}\text { antecipação } \\
\text { osta }\end{array}$ & $\begin{array}{l}\text { Cartografia de risco } \\
\text { Campanhas de prevenção } \\
\text { Programas de ordenamento do território } \\
\text { Rede de estradas florestais } \\
\text { Localização e densidade de pontos de água } \\
\text { Localização de torres de vigilância } \\
\text { Número de bombeiros e localização dos quartéis } \\
\text { Medidas de recuperação de áreas ardidas }\end{array}$ \\
\hline
\end{tabular}

Figura 1 - Componentes da vulnerabilidade e elementos ou variáveis a considerar na análise

O valor económico representa uma expressão monetária da importância dos elementos expostos, assim como dos custos associados à proteção ou recuperação dos mesmos. Esta análise está incluída na dimensão económica da vulnerabilidade, na qual é atribuído um valor, expresso numa quantidade monetária, aos elementos para os quais existe um valor de caráter económico; excetua-se, logo à partida, a vida humana, à qual não é possível atribuir um valor económico.

\subsubsection{Risco de incêndio florestal}

O risco de incêndio florestal resulta da combinação da probabilidade de ocorrência de um incêndio com o grau de vulnerabilidade. O mapa sazonal de probabilidade de ocorrência de incêndio está a ser desenvolvido por outro parceiro do projeto e será, posteriormente, integrado 
com o mapa de vulnerabilidade descrito anteriormente, obtendo-se o mapa de risco de incêndio florestal. A combinação dos diversos níveis de probabilidade com os graus de vulnerabilidade resulta numa escala de risco dividida em cinco classes: reduzido, moderado, elevado, muito elevado e máximo.

\section{2. Áreas de demonstração}

Para demonstrar a aplicabilidade dos produtos desenvolvidos no projeto PREFER, foram selecionadas diversas áreas de interesse. Os mapas de vulnerabilidade, valor económico e de risco serão desenvolvidos, numa fase inicial, para a região do Minho, em Portugal, para o Parque Natural de Los Alcornocales na Andaluzia, em Espanha, e para a província de Carbonia-Iglesias e parte da província de Cagliari e Medio-Campidano, no sudoeste da Sardenha, em Itália (Figura 2).

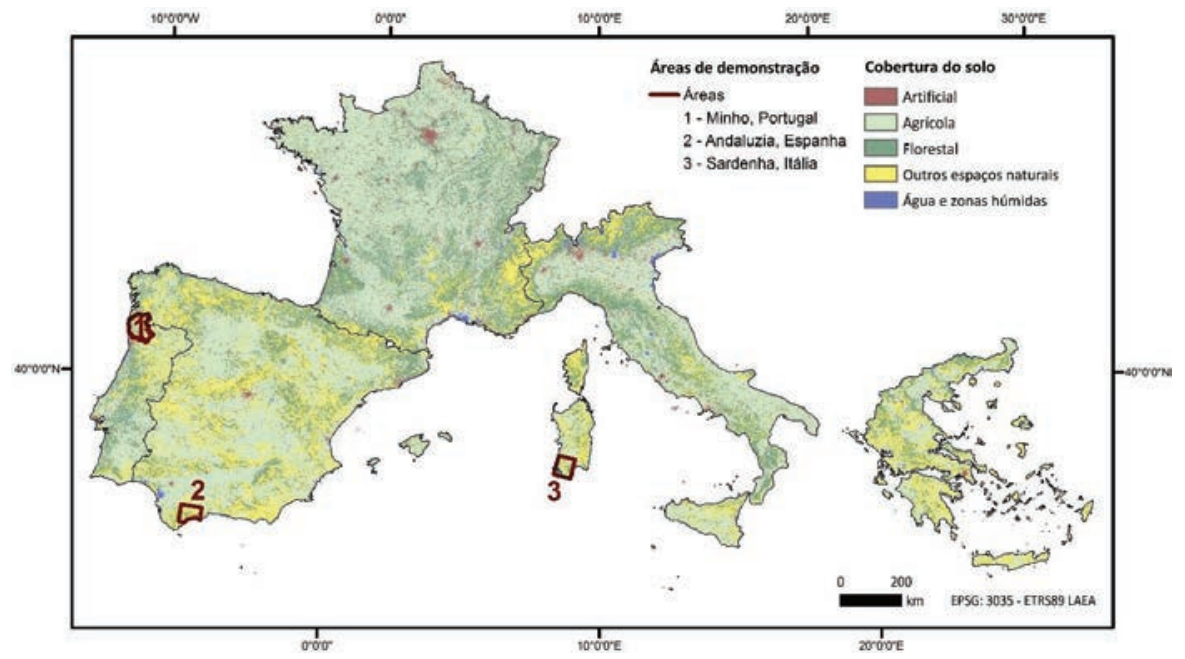

Figura 2 - Áreas de demonstração e cobertura do solo

(Corine Land Cover 2000) dos países em estudo

As áreas de demonstração, que ocupam uma área equivalente a cerca de $11.000 \mathrm{~km} 2$, foram selecionadas por diversas razões: forte incidência de incêndios; presença de diversos tipos de vegetação, não só de espécies tipicamente mediterrâneas (Quercus ilex, Quercus robur, Quercus suber), 
mas também de pinheiro-bravo (Pinus pinaster) e eucalipto (Eucalyptus globulus); existência de áreas protegidas e outras áreas de elevado interesse ecológico; presença de atividades agrícolas.

\subsection{Recolha e processamento de dados}

A análise da vulnerabilidade requer a compilação de dados de diversas fontes, nomeadamente de caráter geográfico. A utilização de imagens de satélite representa uma oportunidade singular de obter dados harmonizados a larga escala e atualizados de forma sistemática, revestindo-se de grande importância ao nível da gestão de incêndios florestais e da proteção de pessoas e bens

O tipo de dados necessários varia em função de cada uma das componentes da vulnerabilidade (exposição, sensibilidade e capacidade de antecipação e resposta). Para a exposição, a obtenção de dados derivados de imagens de satélite para a localização de áreas urbanas e cursos de água, densidade de edifícios e rede de estradas, está a ser realizada com a utilização de satélites de média a alta resolução (Landsat $7 / 8$, SPOT5 e RapidEye). Já para obter, por exemplo, a rede de linhas elétricas, a localização de pontos de água e a localização de edifícios específicos (p. ex., hospitais) usam-se imagens de satélite de muito alta resolução (Worldview-2 e Kompsat-2) e utiliza-se software open-source (ILWIS e GRASS).

As variáveis associadas à sensibilidade, ao valor económico e a parte da capacidade de antecipação e resposta, são, no geral, de base estatística ou espaciais, sendo integradas através de ferramentas SIG. Para cada uma das componentes da vulnerabilidade, está a ser criado um índice composto, os quais são posteriormente integrados num índice final de vulnerabilidade, representado numa escala normalizada de 0-1. A criação de índices intermédios é uma opção atrativa no que respeita à interpretação de dados, uma vez que a informação individual de cada um destes índices pode ser disponibilizada aos utilizadores finais, para apoio à tomada de decisão, de acordo com o esquema de processamento definido para a concretização dos índices que compõem a vulnerabilidade (Figura 3). 


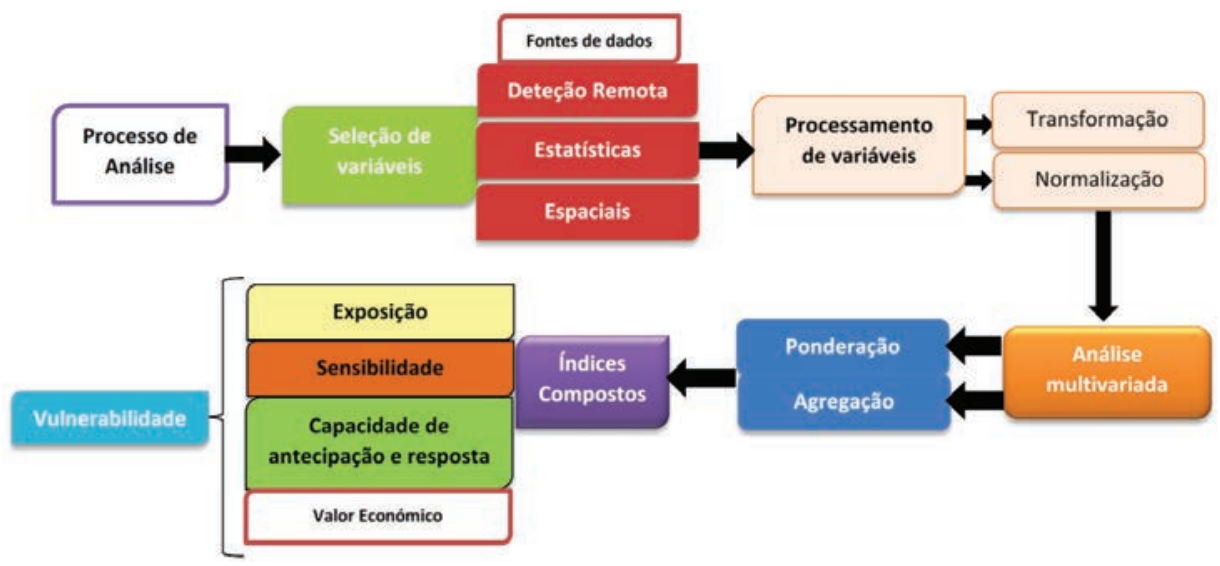

Figura 3 - Esquema de processamento de variáveis e desenvolvimento dos índices compostos que integram a análise de vulnerabilidade

\subsection{Exposição: produtos cartográficos preliminares}

Na Tabela 1 sistematizam-se e nas Figuras 4 espacializam-se 5 das variáveis a ponderar na avaliação da exposição, cuja escala se encontra normalizada de 0-1, para a área de estudo portuguesa. Para o uso/cobertura do solo foram criadas categorias abrangentes a partir dos dados do Corine Land Cover 2006, classificadas de acordo com a maior propensão a sofrerem danos com incêndios e com o tempo necessário à sua recuperação (ex.: as florestas demoram mais tempo a recuperar do que os matos, tendo-lhe sido atribuídos respetivamente ponderações de 1 e 0,8).

O mapa final de exposição é obtido através de um modelo aditivo, em que cada variável corresponde a $1 / 5$ do valor total de exposição. Assim, quanto maior for o número de variáveis representadas na quadrícula, maior é o grau de exposição daquela unidade, uma vez que tem mais tipos de elementos expostos.

Tabela 1 - Exemplo de variáveis a integrar na componente exposição

\begin{tabular}{|c|c|c|c|}
\hline ID & Parâmetros & Dimensão & Variáveis \\
\hline 1 & População & Social & Densidade da população \\
\hline 2 & Uso/coberto do solo & Ambiental/social & Tipo de uso/coberto vegetal \\
\hline 3 & Edifícios & Social & Densidade de edifícios \\
\hline 4 & Infraestruturas & Social & $\begin{array}{c}\text { Densidade de vias de co- } \\
\text { municação (estradas) }\end{array}$ \\
\hline 5 & Áreas protegidas & Ambiental & $\begin{array}{c}\text { \% de área classifica- } \\
\text { da como protegida }\end{array}$ \\
\hline
\end{tabular}




\section{CONCLUSÃo}

O projeto PREFER visa a produção de cartografia múltipla, no intuito de melhorar o suporte técnico e de acesso à informação, reduzir a suscetibilidade à ocorrência de incêndios, tornar mais eficiente a resposta em situações de emergência e auxiliar o processo de recuperação das áreas afetadas em vários países da Europa mediterrânea. Com efeito, a disponibilização de cartografia detalhada, baseada em dados atualizados de forma sistemática e harmonizados em larga escala, a entidades que contribuem para a gestão de riscos, constitui uma oportunidade ímpar para a melhoria do sistema de prevenção e preparação para situações de emergência, a fim de evitar a manifestação de crises.

A produção dos mapas de vulnerabilidade, de valor económico e do risco sazonal de incêndio, para várias áreas de demostração localizadas na bacia do mediterrâneo é da responsabilidade das Universidade de Coimbra e do Minho. Na abordagem conceptual adotada a vulnerabilidade engloba três componentes: exposição, sensibilidade e capacidade de antecipação e resposta, para além da análise do valor económico dos bens expostos. A utilização de dados obtidos a partir de imagens de satélite de alta e muito alta resolução é um aspeto fundamental do esquema processual de variáveis, principalmente aplicados à exposição, que se refere especificamente à distribuição espacial dos elementos que podem sofrer danos caso ocorram incêndios.

Para a exposição, espacializam-se, para a área-amostra em território nacional, algumas das variáveis, nomeadamente as que se relacionam com a densidade populacional, tipos de uso/ocupação do solo, densidade de edifícios, densidade de rede viária e a percentagem das áreas protegidas. No mapa de exposição apresentado utilizou-se um modelo aditivo, atribuindo o mesmo peso a cada uma das variáveis. Todavia, tanto o conjunto de variáveis a integrar na exposição, assim como nas restantes componentes da vulnerabilidade, tal como o método mais adequado de ponderação de cada uma dessas variáveis ainda se encontra numa fase de experimentação. Por outro lado, a disponibilidade e a qualidade da informação estatístico/espacial para as restantes áreas em estudo pode, de igual modo, condicionar a produção final de cartografia. 

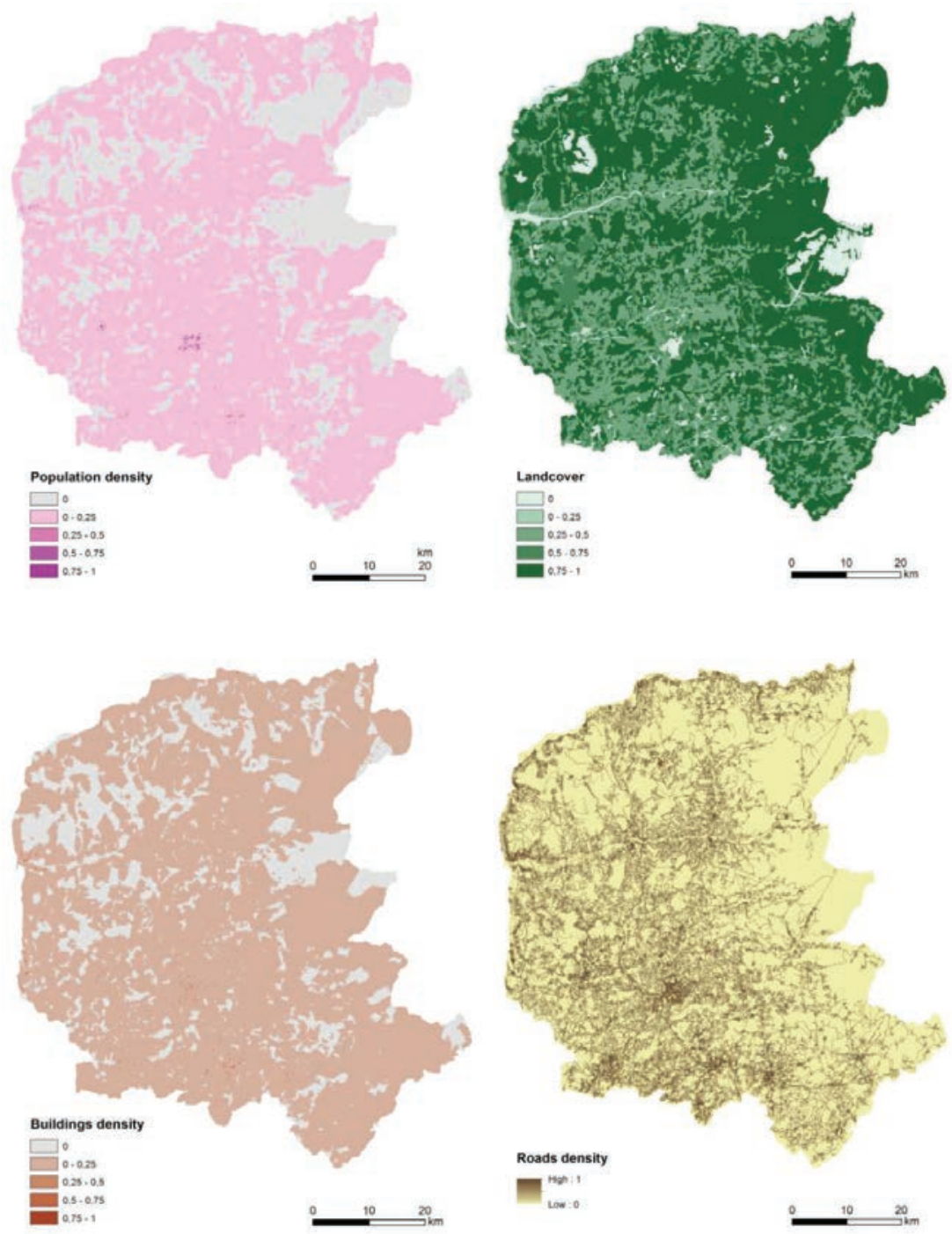

Figura 4 - Espacialização de diferentes variáveis a integrar na componente exposição (densidade populacional; Uso/cobertura do solo; Densidade de construção e densidade de vias de comunicação) 

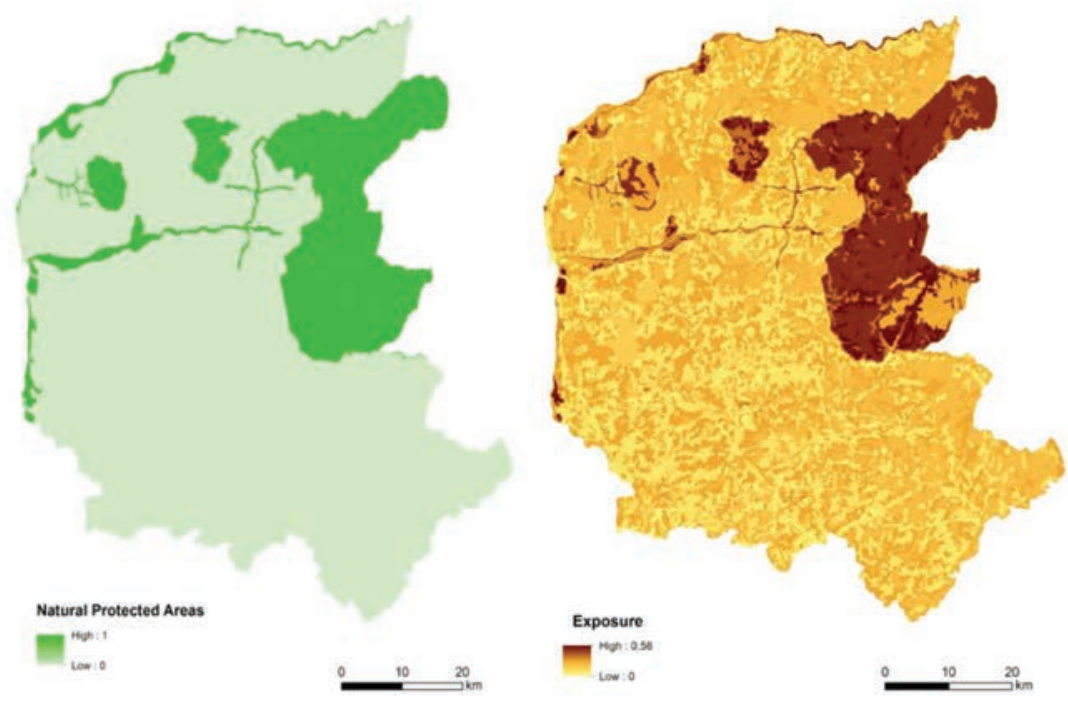

Figura 4 - (continuação) Espacialização de diferentes variáveis a integrar na componente exposição (áreas protegidas) e mapa final de exposição

\section{BIBLIOGRAFIA}

BADIA, Anna et al. (2011) - Identifying dynamics of fire ignition probabilities in two representative Mediterranean Wildland Urban Interface areas. Applied Geography 31, 930-940

BENTO-GONÇALVES, António et al. (2012) - Fire and soils: Key concepts and recent advances. Geoderma 191, 3-13

BIRKMANN, Jörn (2006) - Measuring vulnerability to promote disaster-resilient societies: Conceptual frameworks and definitions. In BIRKMANN, Jörn - Measuring vulnerability to natural hazards: Towards disaster resilient societies, United Nations University Press, 9-54.

BOWMAN, David et al. (2009) - Fire in the Earth System. Science 324 (5926), 481-484

CARVALHO, Anabela et al. (2011) - Forest fires in a changing climate and their impacts on air quality. Atmospheric Environment 45 (31), 5545-5553

CUTTER, Susan (2011) - A ciência da vulnerabilidade: modelos, métodos e indicadores. Revista Crítica de Ciências Sociais [online] 93, Junho 2011: 59-69. Disponível online no endereço url http://rccs.revues.org/165?lang=en (acedido em Junho de 2013). 
DWYER, Edward et al. (2000) - Global spatial and temporal distribution of vegetation fire as determined from satellite observations. International Journal of Remote Sensing 21 (6-7), 1289-1302

JRC, Joint Research Centre (2013) - "Forest Fires in Europe, Middle East and North Africa 2012." Joint report of JRC and Directorate-General Environment. REPORT EUR 26048 EN. Disponível online no endereço url http://forest.jrc. ec.europa.eu/effis/reports/annual-fire-reports/ (acedido em Fevereiro 2014).

LAMPIN-MAILLET, Corinne et al. (2011) - Land cover analysis in wildland-urban interfaces according to wildfire risk: a case study in the South of France. Forest Ecology and Management 261, 2200-2213

LAVOREL, Sandra et al. (2007) - Vulnerability of land systems to fire: Interactions among humans, climate, the atmosphere, and ecosystems. Mitigation and Adaptation Strategies for Global Change 12 (1), 33-53.

LEONE, Vittorio et al. (2003) - The human factor in fire danger assessment. In: Chuvieco, Emilio (ed.), Wildland Fire Danger Estimation and Mapping: The Role of Remote Sensing Data, World Sci., Hackensack, N.J., pp. 143-196.

LOURENÇO, Luciano et al. (2011/12 ) - Causas de incêndios florestais em Portugal continental (1996 a 2010). Cadernos de Geografia 30/31, Faculdade de Letras, Coimbra: 61-80

LOURENÇO, Luciano et al. (2013) - Determination of forest fire causes in Portugal (1996-2010). Flamma 4 (3), 171-175

MARTÍNEZ, Jesus et al. (2008) - "Estimation of Risk Factors of Human Ignition of Fires in Spain by Means of Logistic Regression". Proceedings of the Second International Symposium on Fire Economics, Planning, and Policy: A Global View. General Technical Report PSW-GTR-208, pp. 265-278

MAVSAR Robert et al. (2012) - Economic, legal and social aspects of post-fire management. In MOREIRA, Francisco et al. (eds.) Post-Fire Management and Restoration of Southern European Forests, Springer Netherlands, 45-78

MOREIRA, Francisco et al. (2011) - Landscape-wildfire interactions in southern Europe: Implications for landscape management. Journal of environmental management 92 (10), 2389-2402

OLIVEIRA, Sandra et al. (2013) - "A utilização de dados de satélite no apoio à prevenção e à recuperação pós-incêndios. O exemplo do PREFER na Europa Mediterrânea." Grandes Incêndios Florestais, Erosão, Degradação e Medidas de Recuperação dos Solos, Universidade do Minho, 121-129

PAUSAS, Juli (2004) - Changes in fire and climate in the eastern Iberian Peninsula (Mediterranean basin). Climatic change 63 (3), 337-350

PECHONY, Olga \& SHINDELL, Drew (2010) - "Driving forces of global wildfires over the past millennium and the forthcoming century". Proceedings of the National Academy of Sciences 107(45), 19167-19170 
SAN-MIGUEL-AYANZ et al. (2012) - Land Cover Change and Fire Regime in the European Mediterranean Region. In MOREIRA, Francisco et al. (eds.) PostFire Management and Restoration of Southern European Forests, Springer Netherlands, 21-43

TURNER, Billie et al. (2003) "A framework for vulnerability analysis in sustainability science." Proceedings of the National Academy of Sciences, 100(14), 8074-8079. Disponível online no endereço url http://www.pnas.org/content/100/14/8074.full.pdf (acedido em Novembro de 2013)

UNISDR-UNITED NATIONS INTERNATIONAL STRATEGY FOR DISASTER REDUCTION (2009) - Terminology on disaster risk redution, Geneva, Switzerland: United Nations. Disponível online no endereço url http:// www.unisdr.org/eng/library/lib-terminology-eng\%20home.htm (acedido em Outubro de 2013)

VAZQUEZ, Antonio \& MORENO, Jose (1993) - Sensitivity of fire occurrence to meteorological variables in Mediterranean and Atlantic areas of Spain. Landscape and urban Planning 24: 129-142.

WORLD BANK (2011) - "World Development Indicators 2011". Disponível online no endereço url http://siteresources.worldbank.org/DATASTATISTICS/ Resources/wdi_ebook.pdf (acedido em Junho de 2013) 
Série Documentos

Imprensa da Universidade de Coimbra

Coimbra University Press

2015

- U M

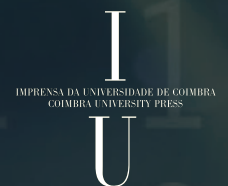

